\title{
Avaliação in vitro de propriedades físico-químicas de cimentos de ionômero de vidro convencionais, após adição de própolis e antibióticos Evaluation in vitro of properties physicist-chemistries of glass-ionomer cements, after addition of propolis and antibiotics
}

\author{
Hellen Cristine FERREIRA \\ Mestranda - Programa de Pós-graduação em Odontologia - Área de Concentração - Dentística - Departamento de \\ Odontologia - Universidade de Taubaté - UNITAU - Taubaté - SP - Brasil \\ Marcos Augusto do REGO \\ Professor Assistente Doutor - Disciplina de Dentística - Departamento de Odontologia - Universidade de Taubaté \\ - UNITAU - Taubaté - SP - Brasil
}

\begin{abstract}
Resumo
O objetivo deste estudo foi avaliar o desgaste pela perda de massa após escovação simulada, a liberação de flúor e a resistência à compressão de dois cimentos de ionômero de vidro, um indicado para restaurações convencionais e outro indicado para a técnica de restaurações atraumáticas (ART), com a adição de antibióticos e própolis. Foram confeccionados corpos-de-prova em cimentos de ionômero de vidro (Vidrion R e Vitro Molar), adicionando-se antibióticos (cefaclor, ciprofloxacina e metronidazol) ou suspensão de própolis (30\% em álcool de cereais) aos mesmos. A seguir observou-se perda de massa por escovação simulada $(n=48)$, resistência à compressão $(n=90)$ e liberação de flúor $(n=60)$ dos corposde-prova. Os dados obtidos foram analisados estatisticamente pelo teste de variância ANOVA e Tukey com nível de significância $\mathrm{p}<00,5$. Analisando-se os resultados obtidos, verificou-se maior perda de massa após escovação simulada para o cimento de ionômero de vidro (Vidrion) adicionado de antibiótico, em relação ao Vidrion (grupo controle), com diferença estatisticamente significativa. Ocorreu maior liberação de fluoretos no cimento de ionômero de vidro (Vitro Molar) adicionado de antibióticos em relação ao Vitro Molar, com diferença estatisticamente significativa. A resistência à compressão foi menor, com diferença estatísticamente significativa, para o cimento de ionômero de vidro (Vidrion) adicionado de antibióticos e de propolis em relação Vidrion. Ocorreu também, diferença estatística na resistência à compressão entre os cimentos de ionômero de vidro Vidrion e Vitro Molar, com superioridade para o primeiro.
\end{abstract}

\section{Palavras-chave}

Cimentos de ionômero de vidro; força compressiva; desgaste de restauração dentária; flúor; estudo comparativo, análise de variância, in vitro

\section{INTRODUÇÃo}

A odontologia tem se direcionado para tratamentos com o mínimo desgaste e perda de tecido dentário sadio na remoção dos processos de cárie. Na busca por materiais que não exijam preparos com desgaste excessivo para sua retenção na cavidade, foram desenvolvidos os cimentos de ionômero de vidro (CIV). Esse material possui propriedades como liberação de flúor, adesividade aos tecidos dentários, não necessitando de materiais intermediários para sua adesão. A incorporação de resina ao CIV tem lhe tem conferido uma melhor resistência e rápido endurecimento.

Em locais com pouco acesso aos serviços dentários, surgiu a técnica da restauração atraumática (ART), na qual realizava-se remoção do tecido cariado com instrumentos manuais e restauração da cavidade com cimento de ionômero de vidro. Na maioria dos casos, o procedimento não necessitava anestesia e demais equipamentos odontológicos. Esta técnica iniciou extensa discussão sobre até onde deve ser removida a dentina cariada e o quanto de bactérias permanecem viáveis no interior da cavidade.

A utilização de fármacos que possam atuar em bactérias que permaneceram no tecido dentário não removido, estão sendo estudados atualmente. Estes antimicrobianos devem apresentar propriedades antibacterianas para atuar na cavidade preparada e quando adicionados ao CIV podem atuar nas bactérias presentes nos túbulos dentinários do tecido remanescente $^{11,23}$.

A própolis apresentou efeitos antimicrobianos sobre $S$. mutans e $S$. sobrinus e foi capaz de inibir a adesão dos mesmos à superfície do vidro, em concentrações 
abaixo da concentração inibitória mínima, sugerindo a possibilidade de uso dessa substância no controle de S. mutans e $S$. sobrinus no biofilme dentário9.

A própolis é uma resina natural utilizada pelas abelhas para proteção da colméia contra a invasão de microrganismos ${ }^{1}$. As variações na composição da própolis são determinadas principalmente pela flora ecológica, ciclos evolutivos das plantas provedoras de resinas, pelos microrganismos em torno da região e fatores climatológicos ${ }^{10}$. A própolis produzida no Brasil apresenta diferenças entre amostras do nordeste e do sudeste. Amostras de própolis do nordeste foram mais efetivas contra $S$. aureus e bactérias Gram-positivas ${ }^{6}$.

A própolis apresenta propriedade de inibir a síntese de polímeros insolúveis em água, inibindo parcialmente a atividade da enzima glicosiltransferase em Streptococcus mutans ${ }^{12}$. Ratos com alto desafio cariogênico, por estarem sem saliva e dieta cariogênica (56\% de sacarose), receberam própolis de duas regiões do país (Rio Grande do Sul e Minas Gerais). Os animais que receberam extrato etanólico de própolis do Rio Grande do Sul apresentaram menor severidade das lesões de cárie, principalmente pela inibição de glicosiltransferases produzidas por $S$. sobrinus. Acredita-se que a maior quantidade de flavonóides seja responsável pelos diferentes efeitos das amostras de própolis ${ }^{13}$. Em amostras do sul do Brasil foram detectadas evidências fitoquímicas de Populus alba como a principal fonte da própolis produzida pela abelha Apis mellifera africanizada ${ }^{21}$.

Extratos etanólicos de própolis (EEP) foram testados pela sua habilidade de inibir a síntese de glicosiltransferase. A efetividade na inibição da atividade da glicosiltransferase na solução foi de 75 a $95 \%$ e nas superfícies de hidroxiapatita em concentrações entre 0.75 e $3.0 \mathrm{mg}$. Esses dados indicaram que EEP apresentaram potencial inibidor da enzima glicosiltransferase em solução assim como adsorvidos em biofilme experimental ${ }^{14}$.

Quando se associou extrato etanólico de própolis com concentrações de 1 e $5 \%$ ou antibióticos (metronidazol, ciprofloxacina e cefaclor) ao cimento ionomérico, avaliou-se a capacidade de inibição de $S$. mutans in vitro e observou-se que EEP a 5\% apresentou ação antibacteriana significativa e as associações de antibióticos tiveram valores de halo na inibição acima de $22 \mathrm{~mm}$, o que se apresentou significativo ${ }^{22}$.

Em estudo sobre a eficácia de misturas de antibióticos (ciprofloxacin, metronidazol, minociclina, amoxicilina, cefaclor, cefroxadine, fosfomicina e rokitamicina) na eliminação de bactérias em dentina cariada e tecidos de lesões endodônticas observou-se efeitos positivos tanto no experimento onde foi feita a cobertura das lesões com misturas de antibióticos por um dia, assim como no experimento por imersão, onde as lesões foram imersas nas misturas de antibióticos. A mistura de ciprofloxacin, metronidazol e cefaclor foi a mais eficiente em diminuir a quantidade de bactérias ${ }^{23}$.

O potencial antibacteriano do cimento de policarboxilato temporário contendo uma mistura de metronidazol, ciprofloxacina e cefaclor a $2 \%$, em lesões cariosas de cavidades preparadas foi avaliado por Hori et al. ${ }^{11}$, 1997. Os autores observaram que as lesões de cárie cobertas pelo cimento preparado com antibióticos foram esterilizadas em um a quatro dias, pois não havia bactéria nos tecidos neste período. Quando se cimentou peça protética com esse cimento, observou-se que em até duas semanas após a cimentação não foram encontradas bactérias, mas após três semanas as bactérias foram encontradas, o que sugeriu microinfiltração marginal.

Existem poucos estudos sobre as alterações físicas que poderiam ocorrer no CIV com adição de antimicrobianos. O objetivo deste estudo foi avaliar o desgaste pela perda de massa após escovação simulada, liberação de flúor e resistência à compressão de dois cimentos de ionômero de vidro, um indicado para restaurações convencionais e outro indicado para ART, após a adição de antibióticos e própolis.

\section{Material e Método}

Para a realização deste estudo foram utilizados dois CIV, um convencional (Vidrion R) e um indicado para ART (Vitro Molar). No Quadro 1 estão expressos os ensaios realizados e os respectivos corpos-de-prova utilizados.

\section{Própolis e antibióticos}

Foi utilizado $0,4 \mathrm{~mL}$ de suspensão de própolis a $30 \%$ em álcool de cereais (Vida Natural Produtos Naturais), equivalente a uma gota, para cada amostra de cimento de ionômero de vidro, que se compõe de uma colher medida de pó e uma gota de líquido do cimento, obtendo-se 5\% de própolis ativo em cada amostra.

Os antibióticos cefaclor, ciprofloxacina e metronidazol, foram misturados em partes iguais, pesados e acondicionados em porções de $0,002 \mathrm{~g}$, obtendo-se $1 \%$ de antibióticos para cada amostra, pois a quantidade média de pó na colher medida foi de $0,22 \mathrm{~g}$. 
AVALIAÇÃO IN VITRO DE PROPRIEDADES FÍSICO-QUÍMICAS DE CIMENTOS DE IONÔMERO DE VIDRO CONVENCIONAIS, APÓS ADIÇÃO DE PRÓPOLIS E ANTIBIÓTICOS

\section{Quadro 1 -Número de corpos de prova de acordo com os materiais utilizados, produtos acrescentados e com os testes realizados}

\begin{tabular}{|c|c|c|c|c|}
\hline \multirow{2}{*}{ Ionômero } & \multirow{2}{*}{ Grupos } & \multicolumn{3}{|c|}{ Leituras } \\
\cline { 2 - 5 } & & Desgaste & Liberação flúor & Compressão \\
\hline \multirow{3}{*}{ Vidrion } & Controle & 8 & 10 & 15 \\
\cline { 2 - 5 } & Própolis & 8 & 10 & 15 \\
\cline { 2 - 5 } & Antibióticos & 8 & 10 & 15 \\
\hline \multirow{3}{*}{ Vitro Molar } & Controle & 8 & 10 & 15 \\
\cline { 2 - 5 } & Própolis & 8 & 10 & 15 \\
\cline { 2 - 5 } & Antibióticos & 8 & 10 & 15 \\
\hline Total & 198 & 48 & 60 & 90 \\
\hline
\end{tabular}

\section{Desgaste por escovação simulada in vitro}

Os corpos-de-prova foram confeccionados utilizando-se matriz própria da máquina de escovação simulada, a qual apresentava quatro perfurações cilíndricas, medindo $3 \mathrm{~mm}$ de altura por $5,0 \mathrm{~mm}$ de diâmetro.

Para o grupo controle Vidrion e Vitro Molar foram utilizadas as instruções do fabricante, utilizando-se uma colher medida de pó para uma gota de líquido. $\mathrm{O}$ pó foi adicionado ao líquido onde era feita a aglutinação, até se obter uma consistência homogênea e brilhante, sem grânulos. O tempo de mistura para o Vidrion R foi de 1 minuto e para o Vitro Molar foi de 30 segundos. O material foi manipulado em placa de vidro grossa, com espátula metálica número ${ }^{24}$.

Para os grupos, Vidrion com própolis e Vitro Molar com propolis, utilizou-se uma colher medida de pó do fabricante e uma gota de líquido mais uma gota de própolis, equivalente a $5 \%$ de própolis ativo no corpo-de-prova.

No grupo Vidrion com antibióticos e Vitro Molar com antibióticos, utilizou-se as mesmas medidas do fabricante adicionando-se $1 \%$ de cefaclor, $1 \%$ de metronidazol e $1 \%$ de ciprofloxacina.

Após a matriz ter sido vaselinada, foi preenchida com CIV, com auxílio de uma seringa centrix, sobre uma placa de vidro e foram cobertas com tira de poliéster, para manter uniforme e plana as superfícies dos corpos-de-prova. Após 15 minutos, os corpos-de-prova foram retirados da matriz, pesados e armazenados em água em quantidade suficiente para cobri-los. Foram realizadas sete pesagens para se assegurar que o CIV não sofreria mais sorção de água ${ }^{4}$.
A seguir, os corpos-de-prova foram removidos de seus reservatórios, com auxílio de pinça clínica, e colocados sobre um papel toalha. Após 2 minutos os corpos-de-prova foram virados, para que os dois lados entrassem em contato com o papel absorvente. Após cinco minutos, desde a remoção da água, o corpo-deprova foi pesado em balança analítica (Quimis AS 210) com precisão de $0,001 \mathrm{~g}$.

Antes da inserção do corpo-de-prova na matriz da máquina de escovação, foi feita a pesagem da massa inicial e então foi utilizada a máquina de escovação in vitro do Departamento de Engenharia Mecânica da Universidade de Taubaté. A máquina foi calibrada para peso de 200g, simulando condições clínicas. Na base giratória foi colocado dentifrício infantil (Tandy) diluído em água na proporção de 1:2. Com o movimento das escovas em contato com o dentifrício sobre os corpos-de-prova, foi produzida espuma que era removida e colocava-se mais dentifrício, permanecendo todo o período com dentifrício sobre os corpos de prova.

A escovação foi realizada em cem mil ciclos por grupo de oito corpos-de-prova, sendo quatro corposde-prova de cada lado. Cada ciclo se completava com o movimento completo de vai e vem da escova sobre o corpo-de-prova. Em média ocorreram 374 ciclos por minuto, perfazendo tempo aproximado de 5 horas para cada grupo. A escova dentária utilizada foi infantil com 22 tufos, macia (Bitufo, referência 0035) que foi trocada a cada cinqüienta mil ciclos. Os corposde-prova também foram trocados de lado na máquina quando completavam cinqüenta mil ciclos $^{8,26}$.

Completados cem mil ciclos, a matriz foi removida da base cilíndrica, lavada em água corrente e colocada 
em aparelho ultrasom (Maxiclean 700, Marconi, USC 700) em água destilada por 10 minutos. Os corpos de prova foram então secados em papel toalha, com dois minutos para cada lado e foram novamente pesados, obtendo-se a massa final. Para se calcular o desgaste obtido com a escovação, foi subtraída a massa final da massa inicial, obtendo-se a perda de massa.

\section{Resistência à compressão}

Para o teste de resistência à compressão, foi utilizado o aparelho VERSAT 2000, do Departamento de Engenharia Mecânica da Universidade de Taubaté.

Para a confecção dos corpos-de-prova, foi utilizada matriz metálica cilíndrica, medindo $5 \mathrm{~mm}$ de diâmetro e $2,6 \mathrm{~mm}$ de espessura. O material foi aglutinado seguindo as instruções de fabricante, conforme item anterior e a matriz foi preenchida com CIV com auxílio de seringa centrix e foram aguardados 15 minutos.

A seguir, os corpos-de-prova foram colocados em frascos com água destilada por 24 horas e a seguir foram secas em papel toalha por cinco minutos e foram colocados na máquina de compressão. O teste foi realizado com carga de $500 \mathrm{Kg}(33,33$ vezes a força mastigatória), que lentamente, à velocidade de $1,00 \mathrm{~mm} /$ minuto, comprimia o corpo-de-prova até o momento de sua máxima resistência e conseqüente fratura. Uma sonda ligada à célula de carga, registrou a carga desde o início do contato no corpo de prova até se obter a fratura, e os dados foram enviadas para computador que apresentava os dados de resistência máxima e média de carga utilizada. O valor da resistência à compressão foi obtido dividindo a força em Newton no momento da fratura pela área do corpo de prova $\left(19,635 \mathrm{~mm}^{2}\right)$, obtendo-se o resultado em Mpa.

\section{Liberação de flúor}

Os corpos-de-prova utilizados no teste de liberação de flúor foram confeccionados em matriz metálica com perfurações cilíndricas medindo $5 \mathrm{~mm}$ de diâmetro e 2,6 mm de espessura. O material foi aglutinado seguindo-se as instruções do fabricante, conforme item desgaste por escovação simulada.

A matriz foi preenchida com CIV, com auxílio de seringa centrix, após ter sido vaselinada e sobre a matriz foi colocada uma tira de poliéster, sobre esta foi colocada uma placa de vidro e um peso de $200 \mathrm{~g}$ por 15 minutos. Os corpos-de- prova foram removidos, pesados em balança analítica e acondicionados individualmente em $200 \mathrm{ml}$ de água deionizada por 24 horas.
A leitura da liberação de flúor foi realizada utilizando-se eletrodo e potencializador da Companhia de Saneamento Ambiental do município de Taubaté (CETESB), para leitura de íons fluoretos liberados na água deionizada onde ficou armazenado o corpode-prova.

O procedimento para determinação do fluoreto em água foi feito através da extração da amostra por destilação em meio ácido (ácido sulfúrico) e a purificação foi feita através de destilação e calor até se obter pH 3,0 e 7,0. Foi feita a calibração do equipamento e a otimização da amostra com potenciômetro (Digimet DM-2), sendo obtidos valores de acordo com os critérios padrões e as concentrações de fluoreto dos corpos-de-prova foram calculados levando-se em conta a diluição efetuada durante a purificação. Todo o procedimento de liberação de fluoreto foi realizado de acordo com o proposto por Clescerl et al..$^{5}$ (1999).

\section{Análise estatística}

Os resultados foram submetidos à análise estatística utilizando-se teste de variância ANOVA e Teste de Tukey, com nível de significância de 5\%.

\section{Resultados}

\section{Desgaste por escovação simulada}

Os valores das médias e desvio padrão da massa inicial, massa final e desgaste estão apresentados na Tabela 1.

Comparando as amostras, não houve diferença estatística entre os grupos Vitro Molar, Vitro Molar com antibióticos e Vitro Molar com própolis. Entre os grupos Vidrion e Vidrion com própolis também não houve diferença estatística. $O$ grupo Vidrion com antibióticos apresentou média maior de desgaste que o Vidrion controle. Não houve diferença estatística no desgaste entre os grupos Vitro Molar e Vidrion.

\section{Liberação de flúor}

Nas médias dos grupos Vitro Molar e Vitro Molar com própolis não ocorreram diferenças estatísticas, mas comparando Vitro Molar e Vitro Molar com antibióticos houve diferença estatística, com maior liberação de fluoretos quando se adicionou antibióticos. Em relação aos grupos Vidrion, Vidrion com própolis e Vidrion com antibióticos não houve diferença estatística entre os grupos, assim como entre os grupos Vitro Molar e Vidrion. Os dados de liberação de fluoretos estão apresentados na Tabela 2. 
AVALIAÇÃO IN VITRO DE PROPRIEDADES FÍSICO-QUÍMICAS DE CIMENTOS DE IONÔMERO DE VIDRO CONVENCIONAIS,

APÓS ADIÇÃO DE PRÓPOLIS E ANTIBIÓTICOS

\section{Resistência à compressão}

Não ocorreram diferenças estatísticas entre os grupos Vitro Molar, Vitro Molar com própolis e Vitro Molar com antibióticos. Comparando Vidrion e Vidrion com antibióticos e Vidrion com própolis houve diferença estatística entre as médias. O grupo controle apresentou maior média de resistência à compressão

que os grupos com própolis e antibióticos. Quando se comparou Vidrion e Vitro Molar, observou-se diferença estatística entre as médias, com maior resistência à compressão do grupo Vidrion. Os valores estão apresentados na Tabela 3 , com suas respectivas médias e desvio padrão.

Tabela 1 - Média e desvio padrão da massa inicial, final e desgaste (g) obtido após escovação in vitro de corpos de prova após adição de própolis e antibióticos ao cimento de ionômero de vidro

\begin{tabular}{c|c|c|c|c|c|c}
\hline \multirow{2}{*}{$\begin{array}{c}\text { IONÔMERO } \\
\text { DE VIDRO }\end{array}$} & \multicolumn{2}{|c|}{ MASSA INICIAL } & \multicolumn{2}{c|}{ MASSA FINAL } & \multicolumn{2}{c}{ DESGASTE } \\
\cline { 2 - 7 } & MÉDIA & $\begin{array}{c}\text { DESVIO- } \\
\text { PADRÃO }\end{array}$ & MÉDIA & $\begin{array}{c}\text { DESVIO- } \\
\text { PADRÃO }\end{array}$ & MÉDIA & $\begin{array}{c}\text { DESVIO } \\
\text { PADRÃO }\end{array}$ \\
\hline VM & 0,23741 & 0,01276 & 0,23013 & 0,01280 & $-0,00729$ & 0,00478 \\
\hline VD & 0,20935 & 0,01840 & 0,20669 & 0,01856 & $-0,00266^{*}$ & 0,00285 \\
\hline VM+P & 0,21984 & 0,57740 & 0,21449 & 0,02101 & $-0,00535$ & 0,00669 \\
\hline VD+P & 0,19026 & 0,03204 & 0,18788 & 0,03236 & $-0,00239$ & 0,00177 \\
\hline VM+A & 0,20430 & 0,01488 & 0,19804 & 0,01327 & $-0,00626$ & 0,00640 \\
\hline VD+A & 0,26033 & 0,01096 & 0,24320 & 0,01262 & $-0,01713^{*}$ & 0,00552 \\
\hline
\end{tabular}

VM: Vitro Molar; VD: Vidrion; VM+P: Vitro Molar com Própolis; VD+P: Vidrion com Própolis; VM+A: Vitro Molar com Antibióticos; VD+A: Vidrion com Antibióticos

* Diferença estatisticamente significativa $(\mathrm{p}<0,05)$

Tabela 2 - Liberação de flúor, média e desvio padrão dos grupos de corpos de prova confeccionados com adição de própolis e antibióticos, em $\mathrm{mg} / \mathrm{L}$

\begin{tabular}{c|c|c|c|c|c|c}
\hline $\begin{array}{c}\text { Corpos-de- } \\
\text { prova }\end{array}$ & VM & VD & VM+P & VD+P & VM+A & VD+A \\
\hline 1 & 1,00 & $<0,15$ & 0,21 & 0,69 & 1,10 & 0,48 \\
\hline 2 & 0,46 & 0,16 & 0,54 & 0,75 & 1,10 & 0,43 \\
\hline 3 & 0,70 & 0,22 & 0,54 & 0,55 & 1,30 & 0,45 \\
\hline 4 & 0,46 & $<0,15$ & 0,38 & 0,90 & 1,00 & 0,50 \\
\hline 5 & 0,45 & $<0,15$ & 1,20 & 0,70 & 1,50 & 0,41 \\
\hline 6 & 0,44 & 3,50 & 1,20 & 1,70 & 0,59 & 0,89 \\
\hline 7 & 0,38 & 0,89 & 0,63 & 1,80 & 0,53 & 1,03 \\
\hline 8 & 0,47 & 1,20 & 0,73 & 1,60 & 1,88 & 0,89 \\
\hline 9 & 0,23 & 0,91 & 1,00 & 1,70 & 1,00 & 0,77 \\
\hline 10 & 0,46 & 0,55 & 1,10 & 1,40 & 1,26 & 0,92 \\
\hline Médias & $\mathbf{0 , 5 0 5 *}$ & $\mathbf{0 , 7 8 8}$ & $\mathbf{0 , 7 5 3}$ & $\mathbf{1 , 1 7 9}$ & $\mathbf{1 , 1 2 6 *}$ & $\mathbf{0 , 6 7 7}$ \\
\hline $\begin{array}{c}\text { Desvio } \\
\text { Padrâo }\end{array}$ & $\mathbf{0 , 2 0 7 8}$ & $\mathbf{1 , 0 2 9 8}$ & $\mathbf{0 , 3 5 2 9}$ & $\mathbf{0 , 5 0 3 3}$ & $\mathbf{0 , 3 9 8 9}$ & $\mathbf{0 , 2 4 4 2}$ \\
\hline
\end{tabular}

VM: Vitro Molar; VD: Vidrion; VM+P: Vitro Molar com Própolis; VD+P: Vidrion com Própolis; VM+A: Vitro Molar com Antibióticos; VD+A: Vidrion com Antibióticos

* Diferença estatisticamente significativa $(\mathrm{p}<0,05)$ 
AVALIAÇÃO IN VITRO DE PROPRIEDADES FÍSICO-QUÍMICAS DE CIMENTOS DE IONÔMERO DE VIDRO CONVENCIONAIS, APÓS ADIÇÃO DE PRÓPOLIS E ANTIBIÓTICOS

Tabela 3 - Valores de resistência máxima à compressão, em Mpa, obtidos nos corpos-de-prova confeccionados com cimento de ionômero de vidro adicionados de própolis e antibióticos

\begin{tabular}{c|c|c|c|c|c|c}
\hline CORPO-DE-PROVA & VM & VD & VM+P & VD+P & VM+A & VD+A \\
\hline 1 & 38,83 & 49,82 & 42,45 & 12,86 & 16,86 & 21,10 \\
\hline 2 & 13,86 & 48,20 & 14,11 & 23,97 & 26,85 & 26,47 \\
\hline 3 & 38,21 & 27,97 & 10,24 & 10,36 & 13,86 & 13,36 \\
\hline 4 & 33,59 & 47,07 & 5,99 & 17,61 & 18,60 & 20,98 \\
\hline 5 & 30,59 & 33,96 & 10,99 & 26,22 & 36,46 & 11,36 \\
\hline 6 & 23,10 & 36,46 & 29,97 & 27,10 & 18,98 & 19,35 \\
\hline 7 & 25,85 & 53,94 & 20,60 & 24,97 & 26,47 & 13,74 \\
\hline 8 & 54,94 & 36,09 & 12,11 & 41,95 & 27,72 & 13,11 \\
\hline 9 & 34,46 & 13,98 & 13,36 & 36,71 & 37,21 & 16,73 \\
\hline 10 & 30,84 & 33,71 & 31,47 & 6,87 & 22,97 & 22,35 \\
\hline 11 & 31,09 & 39,08 & 18,23 & 39,96 & 12,49 & 20,10 \\
\hline 12 & 30,84 & 34,96 & 19,98 & 25,35 & 16,23 & 21,85 \\
\hline 13 & 7,99 & 47,07 & 36,96 & 11,49 & 17,86 & 28,84 \\
\hline 14 & 8,62 & 34,59 & 30,22 & 12,36 & 26,10 & 21,48 \\
\hline 15 & 18,11 & 61,56 & 19,10 & 8,12 & 32,96 & 28,84 \\
\hline Média & 25,815 & $40,785^{*}$ & 22,015 & $21,155^{*}$ & 22,865 & $21,04^{*}$ \\
\hline Desvio Padrão & 12,49 & 11,76 & 9,35 & 11,70 & 7,99 & 5,72 \\
\hline
\end{tabular}

VM: Vitro Molar; VD: Vidrion; VM+P: Vitro Molar com Própolis; VD+P: Vidrion com Própolis; VM+A: Vitro Molar com Antibióticos; VD+A: Vidrion com Antibióticos

* Diferença estatisticamente significativa $(\mathrm{p}<0,05)$

\section{Dıscussão}

Os testes utilizados neste estudo foram realizados para verificar se CIV adicionado de própolis e antibióticos, mantinham suas propriedades físico-químicas. A liberação de flúor, uma das principais características desse material é fator decisivo na sua utilização clíni$\mathrm{ca}^{25}$ e deveria ser mantida ou até aumentada, quando da adição da própolis e antibióticos. A liberação de fluoretos, favorecendo a remineralização dos túbulos dentinários e a liberação de produtos antibacterianos da própolis e antibióticos favoreceriam seu uso na ART, com a remoção da camada externa de dentina infectada e sem dúvida sobre a permanência de bactérias no interior dos túbulos dentinários ${ }^{3}$.

A escolha dos antibióticos cefaclor, metronidazol e ciprofloxacina, foi realizada baseando-se nos estudos de Hori et al. ${ }^{11}$ (1997) e Sato et al. ${ }^{23}$ (1993) que concluíram que esses medicamentos não tinham efeitos colaterais. O metronidazol foi escolhido pois atua em bactérias anaeróbias que são freqüentemente encontradas em regiões profundas de dentina infectada. Entretanto, seu uso isolado não elimina todas as bactérias. Ciprofloxacina e cefaclor são eficientes contra bactérias do biofilme dentário e não apresentam riscos. Com o uso em conjunto com o metronidazol, se mostraram eficientes na cárie dentária.

A resistência à compressão é um fator decisivo para utilização de determinado material ${ }^{20}$, pois é necessário que ele resista aos esforços mastigatórios diretos, sem sofrer fraturas ou deformações, fato que poderia ocorrer ao ser alterada a proporção pó líquido durante a aglutinação do material, quando da adição de uma gota de própolis ou de 0,002 g de pó de antibióticos. Poderia ocorrer também alterações da reação ácido-base pela adição destes diferentes produtos químicos ao CIV. 
A perda de massa com o desgaste pela escovação in vitro, simulando o procedimento clínico do contato das cerdas da escova nas restaurações com o CIV, e causando erosão do material justificaria ou não seu uso clínico. Foi utilizado no presente estudo, escovação no total de cem mil ciclos, de vai e vem da escova, simulando dez anos de escovação de uma restauração ${ }^{19}$.

Os resultados do presente estudo, demonstraram em relação à perda de massa pelo desgaste com escovação simulada, que Vitro Molar e Vidrion não apresentaram diferença estatística entre si, assim como não houve diferença entre Vitro Molar com adição de própolis e antibióticos, e Vidrion com adição de própolis. Por outro lado, com a adição de antibióticos no Vidrion, houve maior desgaste quando comparado ao grupo controle. Segundo Xie et al. ${ }^{27}$ (2000), quando as partículas e a matriz polimérica não formaram cadeias de sal durante o processo de geleificação, observou-se maior desgaste nessas regiões do CIV, o que pode explicar maior fragilidade quando da adição de $1 \%$ de antibióticos.

Em estudo comparativo com amálgama, Mandari et al. ${ }^{18}$ (2001) observaram que ocorreu maior perda de restaurações realizadas com CIV, por desgaste ou dissolução. Esse estudo foi feito com manipulação do material conforme indicação do fabricante, e demonstrou maior perda com o CIV. Em nosso estudo, o material com adição de antibióticos, demonstrou maior desgaste que o grupo controle, parecendo representar possível contra indicação à adição de antibióticos, em forma de pó ao CIV.

Em relação à liberação de fluoretos, houve diferença estatística somente no grupo Vitro-Molar com adição de antibióticos, ocorrendo maior liberação de flúor. Este fato parece favorecer seu uso clinicamente, pois a maior liberação de fluoretos é indicado para uso em ART, para remineralizar superfícies de esmalte ${ }^{15,24-5}$.

A liberação de fluoretos do ionômero de vidro ocorre com maior intensidade nas primeiras 24 a 48 horas. Esse fenômeno decorre da presa lenta do cimento, que desloca maior quantidade de elementos ionicamente ativos nas primeiras etapas da geleificação, onde os íons metálicos do pó são transferidos para o ácido poliacrílico ${ }^{7}$. Por este motivo, realizou-se no presente estudo, a quantificação de liberação de fluoretos no período de 24 horas após a fase inicial da geleificação. A ocorrência de médias na liberação de fluoretos sem diferenças estatísticas entre os grupos estudados em nosso estudo, parece favorecer seu uso clinicamente. A liberação de fluoretos é a principal propriedade do CIV e sua manutenção, mesmo com adição de outros produtos, não descaracterizou o material.
No teste de resistência à compressão realizada na presente pesquisa, ocorreram diferenças estatísticas, principalmente em relação aos materiais dos grupos controle, Vitro Molar e Vidrion. O grupo Vitro Molar apresentou menor resistência à compressão que o cimento convencional. Parece-nos adequado que o Vitro-Molar, indicado para as ART, apresentasse maior resistência à compressão, pois o mesmo é indicado para restaurações classe I de dentes posteriores, que recebem esforços mastigatórios diretos ${ }^{16-7}$.

Houve também diferença entre o grupo controle Vidrion e os grupos Vidrion com antibióticos e Vidrion com própolis, ocorrendo maior resistência à compressão no grupo controle. Estes resultados levam-nos a sugerir atenção quando do uso clínico, pois poderia ocorrer maior perda de material em cavidades restauradas com este cimento modificado pela adição de antibióticos e própolis, com maior possibilidade de fraturas e deformação do material.

É importante observar que mesmo após a adição de antibióticos e própolis, o resultado das médias de resistência à compressão foram superiores ao que se utiliza na mastigação, que segundo Anderson ${ }^{2}$ (1956), apresentou valores entre 6 e $15 \mathrm{Kg}$. Neste estudo, necessitou-se carga muito maior para que o material se fraturasse, no teste de resistência à compressão. $\mathrm{O}$ valor mínimo de carga na compressão no teste com o grupo controle Vidrion, foi de 13,98 Mpa e no grupo Vidrion com própolis, que obteve menor média de resistência, foi de 6,87 Mpa.

A adição de própolis e antibióticos, apresentou, durante a aglutinação, diferenças na coloração e viscosidade do CIV. A própolis produziu coloração amarelada e alterou a viscosidade do material, deixando-o mais fluido, quando comparados com o grupo controle. Entretanto, quando se utilizou $1 \%$ de antibióticos, não houve alteração da cor visível a olho nu, mas o cimento após a aglutinação apresentou menor fluidez, comparada com o grupo controle

Propriedades como resistência à compressão e perda de massa ao desgaste, não devem ser menores que o CIV controle. Ao contrário, estas propriedades dos ionômeros já são inferiores quando comparadas com amálgama e resina, e devem ser estudadas para serem melhoradas. Em relação à liberação de flúor, existem ionômeros que apresentam altas taxas de liberação, portanto, se esses valores se mantiverem, com a adição dos antibióticos, devem produzir benefícios na remineralização de dentes vizinhos e viabilizarão a técnica de restauração atraumática. 
AVALIAÇÃO IN VITRO DE PROPRIEDADES FÍSICO-QUÍMICAS DE CIMENTOS DE IONÔMERO DE VIDRO CONVENCIONAIS, APÓS ADIÇÃO DE PRÓPOLIS E ANTIBIÓTICOS

\title{
Conclusões
}

Avaliando-se os resultados obtidos no presente estudo, pode-se concluir:

- a avaliação do desgaste após escovação simulada, demonstrou maior perda de massa para o cimento de ionômero de vidro (Vidrion) adicionado de antibiótico, em relação ao controle, com diferença estatisticamente significativa;
- ocorreu maior liberação de fluoretos no cimento de ionômero de vidro (Vitro Molar) adicionado de antibióticos em relação ao controle, com diferença estatisticamente significativa;

- a resistência à compressão foi menor, com diferença estatísticamente significativa, para o cimento de ionômero de vidro (Vidrion) adicionado de antibióticos e de própolis em relação ao controle.

\begin{abstract}
The aim of this study was to evaluate the loss of mass after simulated toothbrushing, release of fluoride and compressive strength of two conventional glass ionomer cements, one indicated for conventional restaurations and other indicated for the atraumatic restorations technique (ART), with antibiotics and propolis addition. Specimes in glass ionomer cements (Vidrion R and Vitro Molar), adding antibiotic (Cefaclor, Ciprofloxacina and Metronidazol) or propolis suspension (30\% in cereals alcohol) had been confectioned. Loss of mass for toothbrushing simulated, compressive strength and fluoride release of the specimes were observed. The results were submitted to the non-parametric test ANOVA and Tukey, being that statical significance was consideres when $p<0,05$. The results showed that bigger loss of mass was verified after simulated toothbrushing for the glass-ionomer cements (Vidrion) added of antibiotic, in relation to the Vidrion (control), with statistically significant difference. Higher release of fluoride in the glass ionomer cement (Vitro Molar) added of antibiotics occurred to the Vitro Molar, with statistical significant difference. The compressive strength was lesser, with statistical significant difference, for the glass ionomer cement (Vidrion) added of antibiotics and propolis in relation to the Vidrion. It also occurred, statistical difference in the compressive strength glass ionomer cements Vidrion and Vitro Molar, with superiority for the first one.
\end{abstract}

\section{KEY WORDS}

Glass ionomer cements; compressive strength; dental restoration; wear; fluoride; comparative study; analysis of variance, in vitro

\section{ReferênCIAS}

1. Almeida EC, Menezes H. Anti-inflamatory activity of própolis extracts: a review. J Venom Anim Toxins. 2002;8(2):191-212.

2. Anderson DJ. Measurement of stress in mastication. J Dent Res. 1956;35:664-70.

3. Banerjee A, Watson TF, Kidd EAM. Dentine caries: take it or leave it? Dent Update. 2000;27(6):272-5.

4. Cefaly DFG, Franco EB, Mondelli RFL, Francisconil PAS, Navarro $\mathrm{MFl}$. Diametral tensile strength and water sorption of glass-ionomer cements used in atraumatic restorative treatment. J Appl Oral Sci. 2003;11(2):96-101.

5. Clescerl LS, Greenberg AE, Eaton AD. Standard methods for examination of water \& wastewater. 20th ed. Washington: American Public Health Association; 1998, 1325p.

6. Fernandes Jr A, Leomil L, Fernandes AAH, Sforcin JM. The antibacterial activity of propolis produced by Apis melifera L. and Brazilian stingless bees. J Venom Anim Toxins. 2001;7(2):173-82.

7. Galan Jr J, Namen FM. Ionômeros de vidro. In: Dentística restauradora: o essencial para o clínico. São Paulo: Santos; 1998. p.161-5.

8. Garcia FCP. Avaliação comparativa das resinas compostas fluida em relação à resistência à abrasão (escovação simulada) [dissertação]. Bauru: Faculdade de Odontologia de Bauru; 2001.
9. Gebara ECE, Zardetto CGD, Mayer MPA. Estudo in vitro da ação antimicrobiana de substâncias naturais sobre S. mutans e S. sobrinus. Rev Odontol Univ São Paulo. 1996;10(4):251-6.

10. Geraldini CAC, Salgado EGC, Rode SM. Ação de diferentes soluções de própolis na superfície dentinária: avaliação ultra-estrutural. Pós-Grad Rev. 2000;3(2):37-42.

11. Hori R, Kohno S, Hoshino E. Bactericidal eradication from carious lesions of prepared abutments by an antibacterial temporary cement. J Prosthet Dent. 1997;77(4):348-52.

12. Ikeno K, Ikeno T, Miyazawa C. Effects of propolis on dental caries in rats. Caries Res. 1991;25:347-51.

13. Koo H, Rosalen PL, Cury JA, Park YK, Ikegaki M, Sattler A. Effect of Apis mellifera propolis from two brazilian regions on caries development in desalivated rats. Caries Res. 1999;33:393-400.

14. Koo, H, Vaca Smith AM, Bowen WH, Rosalen PL, Cury JA, Park YK. Effects of Appis mellifera propolis on the activities of streptococcal glucosyltransferases in solution and adsorbed onto saliva-coated hydroxyapatite. Caries Res. 2000;34:418-26.

15. Lang AR, Achutti MAC. Cimento de ionômero de vidro: um material selecionável. Rev Odonto Cienc. 2000;31:43-51.

16. Lo ECM, Homgren CJ. Provisión of atraumatic restorative treatment (ART) restorations to chinese pre-school children:a 30 month evaluation. Int J Paediatr Dent. 2001;11:3-10. 
AVALIAÇÃO IN VITRO DE PROPRIEDADES FÍSICO-QUÍMICAS DE CIMENTOS DE IONÔMERO DE VIDRO CONVENCIONAIS, APÓS ADIÇÃO DE PRÓPOLIS E ANTIBIÓTICOS

17. Lo ECM, Luo Y, Fan MW, Wei SH. Clinical investigation of two glass-ionomer restoratives used with the atraumatic restorative treatment approach in China: two years results. Caries Res. 2001;35:458-63.

18. Mandari GJ, Truin GJ, van't Hof MA, Frencken JE. Effectiveness of three minimal intervention approaches for managing dental caries: survival of restorations after 2 years. Caries Res. 2001;35:90-4.

19. Nagen Filho H. Abrasão e textura superficial de resinas compostas. Salusvita. 1995;14(1):1-9.

20. Navarro MFL, Pascotto RC. Cimentos de ionômero de vidro. In: Cimentos de ionômero de vidro: aplicações clínicas em Odontologia. São Paulo: Artes Médicas; 1998. p.12-20.

21. Park YK, Alencar SM, Aguiar CL. Botanical origin and chemical composisition of Brazilian propolis. J Agric Food Chem. 2002;50(9):2502-6.

22. Pinheiro SL, Simionato MRL, Oda M. Atividade antimicrobiana in vitro dos cimentos de ionômero de vidro associados a própolis ou a antibióticos. Rev Assoc Paul Cirur Dent. 2003;57(3):.

23. Sato $T$, Hocino E, Uematsu H, Noda T. In vitro antimicrobial susceptibility to combinations of drugs of bacteria from carious and endodontic lesions of human deciduous teeth. Oral microbial Immunol. 1993;8:172-6.
24. Smales RJ, Gao W. In vitro caries inhibition at the enamel margins of glass ionomer restoratives developed for the ART approach. J Dent. 2000;28:249-56.

25. Tenuta LMA, Pascotto RC, Navarro MFL, Francischone CE. Liberação de flúor de quatro cimentos de ionômero de vidro restauradores. Rev Odontol Univ São Paulo. 1997;11(4):249-53.

26. Wang L. Avaliação comparativa da resistência à abrasão de resinas compostas "condensáveis", submetidas à escovação simulada, através da alteração de massa e da rugosidade superficial [dissertação]. Bauru: Faculdade de Odontologia de Bauru, 2001.

27. Xie D, Brantley WA, Culbertson BM, Wang G. Mechanical properties and microstructures of glass-ionomer cements. Dent Mater. 2000;16(2):129-38.

Recebido em:31/05/05

Aprovado em: 09/06/05

Prof Dr. Marcos Augusto do Rego R. José Pereira dos Santos 233 - Urbanova

São José dos Campos - ESWP

Tel: 01239491020

marcorego@uol.com.br 